\title{
Environmental Character: Environmental Feelings, Sentiments and Virtues
}

\author{
Geoffrey Frasz \\ (College of Southern Nevada in Las Vegas, Geoffrey.Frasz@csn.edu)
}

\section{Introduction: The Incompleteness of EVE}

Currently theories and accounts of Environmental Virtue Ethics (EVE) focus on the character of various environmental figures and giving an account of various virtues from an environmental consideration. For instance, Ron Sandler (2007) in his full theoretical account connecting virtue ethics with environmental ethics argues that an ethic of character can and should be informed by environmental considerations. Yet applied and theoretical work in EVE remains incomplete for several reasons. First, there has been little work connecting moral feelings and moral sentiments to environmental concerns (see: Partridge 1996; Steverson 2003; Callicott 1990; Colins \& Barkdull 1995; Bowles 2008; for a criticism of using moral sentiments as a basis for environmental thought, see: Fieser 1993). While much has been done with the environmental virtues that are associated with these feelings/sentiments, a full theory of EVE will need to develop what these sentiments are and how they connect to environmental traits of character making up the bulk of current work on EVE. Second, a full theory of EVE must provide an account of the nature of strength of character regarding these virtues. While it is good to feel a desire to care for nature and a concern that this desire be reflected in the behaviours that make up one's character. Yet to make sure this concern is reflected in action requires an account of how strength of will plays a role in maintaining environmentally grounded action, even sacrifice. Such an account will also have to explain the phenomena of weakness of will when attempts are made to adopt a better, environmentally sensitive set of actions and modify one's character to reflect environmental concerns. Furthermore, while autonomy is often held necessary for doing the right thing, how this selflegislating stance can be connected to an environmental sense of the interconnectedness of all things remains still undone. But even if full theory of EVE provides account of sentiments, moral strength and virtuous dispositions that together all form a basis for an environmentally informed moral character, it will remain incomplete.

To be complete EVE it must also provide an account of the wisdom to articulate an account of what is an environmentally good life. It is this last point I will address in this paper. Without an account of environmentally informed wisdom, an environmentally good person will remain morally blind. 
Environmental wisdom is needed to give direction and inform decisions along the way of living an environmentally good life. Coupled with a full account of what kind of person EVE would have us be, there is needed an account of an environmentally wise person, someone who has a sophisticated understanding of the [natural] world and is adept at living a morally satisfying life informed by that understanding. Such a full account of environmental wisdom would be beyond the scope of this paper. This paper will focus on the connection between environmental sentiments and environmental virtues. I will argue that it can be shown how the two are related and an account of a distinctive environmental sentiment of a feeling towards natural entities can complement the environmental virtue of openness.

\section{Environmental Emotions and Sentiments}

It is commonly held that being able to experience moral emotions is a sign of a person able to function morally well. It is further held that a person who can experience moral emotions such as guilt or shame, admiration, disgust, remorse, regret, outrage, and sympathy has the necessary psychological make up that is part of being a morally good person. To lack the ability to frequently experience these feelings indicates a person of a poor moral character. Thus we claim that a psychopath or sociopath is not morally a good person. When a person has developed a moral generalize feeling for the good over time, we hold that such a person has developed moral sentiments. These can be understood as higher-order feelings, motivational dispositions that incline a person towards the good (Rawls 1971, p. 479). We consider people to be morally good when they have internalized moral norms and are motivated to act out of a sense of what is good, rather than a sense of punishment or reward. There are a variety of moral sentiments that people may feel as motivating them: duty, honour, caring, nobility, to name some. In the spirit of trying to characterize what makes up the moral psychology of an environmentally good person, we can ask what might be some distinctive environmental sentiments, emotional dispositions that regularly motivate people to engage in environmentally good actions. Unfortunately, there has been little work connecting moral feelings and moral sentiments to environmental concerns (see: Partridge 1996; Steverson 2003; Callicott 1990; Colins \& Barkdull 1995; Bowles 2008; Fieser 1993).

One such environmental sentiment involves a positive feeling towards natural entities or towards Nature as an interconnected whole. It is a feeling not just of love and admiration of natural entities, but a feeling of being in touch with the entities as they are in themselves without reference to any further human utility. This is a feeling of openness to any value, objective or subjective, intrinsic or inherent, anthropocentric or non-anthropocentric that a natural entity may have. It is a response to the organism or entity for what it can convey to us. It is a feeling that is captured by the fundamental sense of the 
word pathos. While today the word primarily refers to expression of pity or sympathy, pathetic in a root sense involves the capacity to feel what there is to feel from another, whether person or any other entity. While there is no specific word that refers to the kind of feeling, the closest word might be "openness."

This is the feeling identified by Jay McDaniel (1986) in his discussion of the attitudes towards natural entities in the work of the geneticist Barbara McClintock. In McClintock there was an "appreciative and intuitive apprehension of an organism" (McDaniel 1986, p. 44). This 'feeling for the organism' is a manifestation of the environmental virtue of openness. In this case it is an openness to each plant in her research fields, an openness to what each plant had to say.

This openness led to a three-fold apprehension of the organism. First, such openness reveals any organism in Nature as unique. No two organisms are exactly alike and openness to them allows one to experience and appreciate the inherent or intrinsic worth of each creature. There are always going to be more things that we can learn from each individual organism if we can keep from sliding into the arrogant posture that says "If you've seen one redwood, you've seen them all." Second, openness to natural entities can reveal organisms as mysterious others. Such feeling carries with it the awareness that there is always something wholly other to each organism. The possibility of each creature being only partially knowable by science stands as a direct contrast to the arrogant attitude that sees living beings as fully knowable. The otherness of each organism is recognizable only by having an openness to the 'otherness' of each creature. Arrogance is blind to the fundamental mystery of the other and the uniqueness of each creature would dissolve in the attitude that rejects the distinctiveness of each creature. Third, openness reveals each creature as a fellow subject, a locus of intrinsic value, worth and respect. This feeling for the organism involves an openness to the goals, concerns, and intrinsic needs of any or all creatures over and beyond the instrumental value they might have for humans.

The focus on the individual organism can be broadened to include a feeling for or an openness to ecosystems, natural areas or events, or to Nature as a whole. Such an openness reveals a basic interconnectedness between all natural entities. It challenges the idea of individual entities as fundamentally atomic, isolated, and unconnected things. The arrogant attitude of a person who thinks he or she is truly removed from the consequences of his or her action is called into question by this feeling for basic interconnectedness. To be open to Nature is to recognize that a person is one subject among others interwoven in a net of relations. At a fundamental level I am, as Ortega y Gasset pointed out, myself and my circumstance. While contemplating Lake Solitude in the Rocky Mountains Holmes Rolston, III asks: "Does not my skin resemble this lake surface? Neither lake nor self has independent being: both exist in dynamic 
interpenetration across a surface designed for passage and exchange, as well as for delimination and individuation" (Rolston III, p. 224). Note how, in his openness to the lake and its surroundings, Rolston does not lose his sense of self completely, recognizing that an essential feature of living is to be in symbiosis, to stand in reciprocal relation to other natural entities. Nature provides to the 'open' person an experience of distinction as well as connection. Of this feature of Nature Rolston says:

To her teasing, her relentless stimulus, we respond in a 'standing out,' an existence, where the I is differentiated from the Not-I. The environment moves; we are moved, but then reaction is elevated into agentive action. Ecological prodding brings forth the ego. "The landscape thinks itself in me, and I am its consciousness" (Cezanne) (Rolston III, p. 225).

Through an openness to wildness the self can discover itself in this intimate relation with Nature. But also in this encounter with wildness Rolston discovers the mysterious other mentioned earlier. In his openness to Nature he discovers not only a connection but an opposition that offers a chance to realize a needed complement to himself that can no longer be found in civilized life. Of this experience of existing in the natural world Rolston says that with this

there is a communion, but of opposites. The medium that a person is in and of, he or she is also over and against. When the person encounters a world different from himself, he faces a centrifugal wildness which, if unresisted, will disintegrate his centripetal self, but which, if withstood, may be incorporated and domesticated. To travel into the wilderness is to go into what one is not, so that in returning to and turning from its natural complement, mind grasps itself. I encounter an other of which I have the greatest need. Thus journey here is an odyssey of the spirit traveling afar to come to itself (Rolston III, p. 225).

The danger to the self is what makes the closed person, the environmentally arrogant person, so readily willing to destroy the natural world. Perceiving perhaps at an unconscious level the fundamental challenge to the self, the environmentally arrogant person is willing to destroy the threat to self rather than take to challenge to confront the mysterious other and return to the domesticated world with an expanded sense of self.

And in this encounter the mysterious other is revealed not to be a mere object, but another subject with its own telos. An end which has its own intrinsic worth to be respected, whether it be a single corn seedling or an entire wilderness area. Through the feeling of openness to nature a person thrives in between the impoverished self-closed to the enriching encounters possible with nature and the disvalued self that refuses to place itself within Nature as a valued subject among others, unwilling to say "I" to the "Thou" of nature. 


\section{From Environmental Sentiments to Environmental Virtues}

When this environmental sentiment has been internalized in a person to the degree that responding this way to natural entities has become an integral trait of a person's character we can speak of openness becoming an environmental virtue (Aristotle 1962, v. 1098a10).

So far I have been speaking of distinctive environmental virtues. One immediate challenge is to show that there are such virtues, and that EVE is not merely an extension of traditional virtue ethic thinking into environmental concerns. This objection has been raised and answered before (Frasz 2004). But another defence can come from looking at the way Aristotle himself objectively grounds virtues and by showing that his grounding is incomplete and, when expanded can allow for distinctive environmental virtues.

As argued by Martha Nussbaum (1988, pp. 32-39; French, Uehling, \& Wettstein 1988) ${ }^{1}$, Aristotle in his Ethics $(1962$, ch. 2.7, 3.5, 6) begins with "a characterization of a sphere of universal experience (what Nussbaum calls 'grounding experiences') and choice, and introducing the virtue name as the name (as yet undefined) of whatever it is to choose appropriately in that area of experience." He then will flesh out his account what the term means and why it is the better account than rival accounts.

Aristotle identifies first various spheres of human experience where people have to make various choices. These are areas that contain experiences that are common to more or less any human life. They involve things that most people have to address in living their lives as human beings. For example, it is a feature of human life that we can choose how to respond to danger and threats to our life, we can act in different ways. Courage would refer to those appropriate responses and actions, while cowardice and foolhardiness refer to inappropriate responses and actions. Second, he asks, what is to choose and respond well within such a sphere? or hat is it to choose or act in poor, deficient, or excessive way in such a sphere? His "thin" list of virtuous terms reflect whatever it is to be stably disposed to act appropriately in that sphere. We may or may not have a good word such responses or actions. His "thick" account is his reasoned defence of one particular account of a virtue and why it is to preferred over some other account.

What Environmental Virtue Ethics adds to this account is to describe the missing "environmental" grounding experiences of human life and then "thicken" the definitions of the virtues of the virtues by showing how particular new definitions provide an understanding of better ways to act or choose appropriately in these spheres. Different accounts of "green" virtues can be

${ }^{1}$ Nussbaum points out that traditionally for various spheres of human life there are identified particular virtues. In the sphere of fear of important damages, especially death, there is the virtue of courage, in the management of personal property, where others are concerned there is the need for generosity, etc. These are objective spheres of human concern that transcend relativistic cultural concerns. 
seen as different answers to how to live well or in an excellent way with the natural world. We can assess the definitions as different solutions in light of how well they deal with the complexities of living in harmony with natural world. Some EVE theorists have already extended traditional virtues into these environmental grounding experiences. ${ }^{2}$ What I argue for here is a distinctive "environmental" virtue, that of openness as a way or habit of character in responding to the "Other" of natural entities of all kinds.

An environmental virtue is a perfection of one's character regarding the relationships between self and the natural world, a person with a good environmental character should be able to flourish more fully in such relationships and in personal development. Having environmental virtues such as openness and leading an environmentally good life makes flourishing in a biotic community more likely. I follow James Liszka when he describes a flourishing life as

one that allows you to enjoy the real pleasures of life, to engage in highly qualitative relationships with others, to attain a certain amount of wealth in a respectable way, and to reach a certain well-deserved status and recognition, but all within the context of virtuous living (Liszka 1998, p. 238).

When this openness is part of one's disposition to respond to the natural work and its members, one is more likely to establish the kind of qualitative relationships Liszka describes.

One way to describe the nature of this characteristic of openness is a negative way, by describing what it is not. i.e., by describing the extremes that characterize the vices associated with this virtue. On one end of the scale is the arrogance of overbearing self-importance. This trait closes a person off to any experience of value or worth in nature other than seeing it merely have an instrumental value for achieving personal ends. It is also a fixed perspective on the world, one that cannot see beyond oneself and what matters to oneself. It is the arrogance that one has all the answers, all the insights, and all the means for achieving a full human life. What disturbs us in an arrogant person is the 'closed-ness' of his or her views, the narrow or closed-mindedness of a person who is incapable or unwilling to consider a different viewpoint. As intolerance or narrow-mindedness towards other persons is considered a vice, an extension of this trait towards other natural entities is an environmental vice. We consider a person who is emotionally closed off to Nature as spiritually dead, incapable of appreciation of natural things except in terms of resources solely for human ends. And as such a person may very well live a life of limited love and affection towards other people, and may see them only insofar as they

2 Sandler (1988) provides a list of "environmental" virtues. Philip Cafaro (2010) lists patriotism as an environmental virtue, as well as arguing that gluttony is an environmental vice. See also Cafaro (2005). Geoffrey Frasz (2005) has described benevolence as an environmental virtue. 
can contribute to one's own needs. Would not a person who is closed off emotionally to natural entities also live a shallow life of limited love? While there is no guarantee that being open to Nature will also manifest itself in openness to other people, it can be argued that someone who is more open to other people as they are in themselves, could be more likely to expand this sense of openness to nonhumans because there are fewer boundaries between the person and other beings. And as the arrogant person is less likely to consider the consequences of an action except as they impact on him or herself, the environmentally arrogant person, one who is closed off to natural entities as they are in themselves, is less likely to consider the environmental effects or consequences of actions towards nature. It is widely agreed that this insensitivity to environmental effects has led to the environmental crisis facing us today. And contributing to this crisis is the arrogance of perceiving nature only in instrumental terms, to be closed off to natural entities as they are in themselves. It is also the insensitivity to the feelings of nonhuman entities which manifests itself in uncaring cruelty in the way animals are used for food, sport, or research. The arrogant attitude is blind to this value for it can conceive of other creatures only as instrumental objects, not as subjects in their own right of a life. To be able instead to say "Thou" to another creature requires that I be open to the distinctiveness of that organism as subject of a life ${ }^{3}$. The environmental virtue of openness is necessary to be able to intuitively apprehend this subjectivity in others. Consequently, openness fosters respect for each organism as a subject with intrinsic value to it. And the honest recognition of subjectivity requires that one be open to subjectivity in other organisms and in oneself as well. Arrogance is one end of the scale and is a vice that has been widely noted and discussed. On the other end of the scale is a trait less widely discussed but still a vice nonetheless. It is the trait of an excessive lack of self or of worth of the individual in environmental matters. This trait becomes manifested in those environmental ethics that propose to extend moral consideration to some or all living things. Sufficient it now to indicate that this attitude is something that is often mentioned in discussions of environmental fascism. This discussion is examined in (Callicott 2013, pp. 225-226).

By focusing on these extremes of environmental openness it is possible to delimit the range of what would be an acceptable scope to a 'proper' openness of natural entities. But there is also a need to specifically develop the features of this virtue. In a positive sense 'openness' is an environmental virtue that establishes an awareness of oneself as part of the natural environment, as one natural thing among others. A person who manifests this trait would be

${ }^{3}$ It does not follow that such openness requires us not to use, consume, or even kill other organisms. To be subject of a life does seem to involve a respect for that life, but as is the case with many hunter gatherer peoples, the prey is respected and even thanked for what it provides yet still is killed and eaten. 
one who is neither closed off to the humbling effects of Nature, nor one who loses all sense of individuality when confronted with the vastness and sublimity of Nature. Such a person is capable of feeling a response triggered by natural events, who is able to let Nature speak to him or her. It is a receptiveness to natural entities as they are in themselves. We value openness to other people as an esteemed quality of character since it fosters feelings of love and appreciation for other persons. I believe that as this quality is developed between persons, when it is coupled to an understanding of human beings existing within Nature, that openness to Nature will be more likely to result. Furthermore, I hold that fostering such an openness to natural entities can reinforce a sense of openness to other persons ${ }^{4}$, a quality which we already esteem and value. To the challenge of why should people develop this virtue I reply that not only will it develop an attitude that values Nature for its own sake, but will also contribute to the development of qualities of openness to other people. If a critic is willing to admit to the value of openness between persons, I reply that that character trait can be fostered by activities that 'open up' a person to Nature. One such activity is the experience of wilderness solitude.

When the experience of community with other persons is replaced by the experience of solitude in wilderness, then the best possibility exists for encounter with the natural order of things. Again, there is no guarantee that such an awareness will, indeed, occur. But such a condition of being alone in wilderness does make such an encounter more likely. The experience of wilderness solitude, whether by a wilderness lake, in a wild cave, or among the peaks of a mountain range, can open up a person to an awareness of nature of things, as they are for themselves, as they exist independent of human needs or concerns. One goes to wilderness to encounter the natural order, to discover one's place within this order, to be open to what Nature has to say. In this encounter one discovers that one is both self and circumstance, that the self is a semi-permeable membrane. One is neither closed off to Nature nor does one lose the sense of self-worth. And returning from the wilderness to the community of other persons, one can have the further appreciation of persons as other others who exist in a community of interdependence with roots in the natural order. But in order to fully appreciate all the members of this mixed biotic community, it is necessary that a person be able to first feel what Nature has to reveal. When responding with this environmental sentiment becomes a disposition of one's character, then a person has begun to cultivate openness as an environmental virtue.

${ }^{4}$ A critic may complain that after a sojourn into the wilderness he or she often experiences a hostility or antipathy towards people in the urban areas, especially those who do not seem to care for nature. I reply that this anger is directed more at the actions of certain people and not at each and every person, human beings having some inherent worth that needs to recognized and honoured. It is often easy to forget the admonishment to "hate the sin, but not the sinner." 


\section{Further Work In for a Full Theory of Environmental Character}

This paper represents an approach to complete EVE by showing a connection with the environmental virtues that are associated with environmental feelings/sentiments. However, a full theory of EVE will need to develop what these are and how they connect to environmental traits of character making up the bulk of current work on EVE. Furthermore, a full theory of EVE must also provide an account of the nature of strength of character regarding these virtues. While it is good to feel a desire to care for nature and a concern that this desire be reflected in the behaviours that make up one's character. Yet to make sure this concern is reflected in action requires an account of how strength of will plays a role in maintaining environmentally grounded action, even sacrifice. Such an account will also have to explain the phenomena of weakness of will when attempts are made to adopt a better, environmentally sensitive set of actions and modify one's character to reflect environmental concerns. While autonomy is often held necessary for doing the right thing, how this self-legislating stance can be connected to an environmental sense of the interconnectedness of all things remains still undone. But even if a theory of EVE provides account of sentiments, moral strength and virtuous dispositions that together all form a basis for an environmentally informed moral character, it will remain incomplete.

To be complete an account of a good environmental character must provide an account of the wisdom needed to articulate and guide an environmentally good life. Without an account of environmentally informed wisdom, an environmentally good person will remain morally blind. Environmental wisdom is needed to give direction and inform decisions along the way of living an environmentally good life. Coupled with a full account of what kind of person EVE would have us be, there is needed an account of an environmentally wise person, someone who has a sophisticated understanding of the [natural] world and is adept at living a morally satisfying life informed by that understanding. What is further needed is an account of an environmentally informed account of wisdom and the way it infuses the character of an environmentally wise person (One initial attempt at providing such an account of "green" wisdom is found in: Frasz 2011). This addition of an environmental account of wisdom gives an environmental spin on a well-worn metaphor: environmentally grounded moral sentiments makes us desire a worthwhile destination, but an environmental sound vision tell us where to look. Moral strength may provide us with the will power to do what is necessary to go the distance to attain this environmentally informed destination, but environmentally grounded judgment tells us when it is best to exercise strength of will in environmental situations. Environmental virtues keep us on the path and from developing environmental vices that cause us to stray from it, but an environmentally grounded understanding of deliberation shows us how to best 
use the path to get to that destination. With this addition of a green understanding of wisdom, it will be possible to have the necessary environmental grounding that we would want for an environmentally good character.

\section{References}

Aristotle. 1962. Nicomachean Ethics. Trans. M. Oswald. Indianapolis: Library of Liberal Arts.

Bowles, S. 2008. "Policies Designed for Self-Interested Citizens May Undermine 'The Moral Sentiments." Science, Vol. 320(5883): 1605-1609.

Cafaro, Ph. 2005. "Gluttony, Arrogance, Greed, and Apathy." In Sandler, R. \& Ph. Cafaro (eds.) Environmental Virtues Ethics (pp. 135-158). Lanham, MD: Rowman \& Littlefield.

Cafaro, Ph. 2010. "Patriotism as an Environmental Ethic." Journal of Agricultural and Environmental Ethics, Vol. 23(1-2): 185-206.

Callicott, J. B. 1990. “The Case against Moral Pluralism.” Environmental Ethics, Vol. 12:99-124.

Callicott, J. B. 2013. Thinking Like a Planet: The Land Ethic and the Earth Ethic. Oxford: Oxford University Press.

Colins, D. \& J. Barkdull. 1995. "Capitalism, Environmentalism, and Mediating Structures." Environmental Ethics, Vol. 27: 227-244.

Fieser, J. 1993. "Callicott and the Metaphysical Basis of Ecocentric Morality." Environmental Ethics, Vol. 15:171-180.

Frasz, G. 2004. "Is Environmental Ethics 'Mere' Extensionism?" Akademia.edu. URL: https://www.academia.edu/787589/Is_Environmental_Virtue_ Ethics_Mere_Extensionism (retrieved on 15.07.2016).

Frasz, G. 2005. "Benevolence as an Environmental Virtue" In Sandler, R., Ph. Cafaro (eds.) Environmental Virtues Ethics (pp. 121-134). Lanham, MD: Rowman \& Littlefield.

Frasz, G. 2011. "Wise EVE: A Green Account of Wisdom and Its Connection to Environmental Virtues." Akademia.edu. URL: https://www.academia.edu/787550/WISE_EVE_A_GREEN_ACCOUNT_ OF_WISDOM_AND_IT_S_CONNECTION_TO_ENVIRONMENTAL_VIRTUE $S$ (retrieved on 15.07.2016).

French, P. A., T. E. Uehling, \& H. K. Wettstein. 1988. Ethical Theory: Character and Virtue. Notre Dame, IN: University of Notre Dame Press.

Liszka, J. 1998. Moral Competence. Upper Saddle River, NJ: Prentice Hall.

McDaniel, J. 1986. "Christian Spirituality as Openness to Fellow Creatures." Environmental Ethics, Vol. 9: 37-46.

Nussbaum, M. 1988. "Non-Relative Virtues: An Aristotelian Approach." Midwest studies in philosophy, Vol. 13(1): 32-53. 
Partridge, E. 1996. "Ecological Morality and Nonmoral Sentiments." Environmental Ethics, Vol. 18: 149-163.

Rawls, J. 1971. A Theory of Justice. New York: Random House.

Rolston, III, H. "Lake Solitude: The Individual in Wildness." In H. Rolston, III Philosophy Gone Wild. Buffalo, NY: Prometheus Books.

Sandler, R. L. 2007. Character and Environmental: A Virtue-Oriented Approach to Environmental Ethics. New York: Columbia University Press.

Steverson, B. 2003. "Evolutionary Emotivism and the Land Ethic." Social Philosophy Today, Vol. 19: 65-77. 
Geoffrey Frasz

(College of Southern Nevada in Las Vegas, Geoffrey.Frasz@csn.edu)

\title{
Environmental Character: Environmental Feelings, Sentiments and Virtues
}

\begin{abstract}
An argument is made that to further develop the field of environmental virtue ethics it must be connected with an account of environmental sentiments. Openness as both an environmental sentiment and virtue is presented. This sentiment is shown to be reflected in the work of Barbara McClintock. As a virtue it is shown to a mean between arrogance and the disvaluing of individuals, a disposition to be open to the natural world and the values found there. Further development of EVE is then shown to require a connection with an account of environmental wisdom.
\end{abstract}

Keywords: environmental ethics, Barbara McClintock, virtue ethics, environmental virtue ethics

Ethics in Progress (ISSN 2084-9257). Vol. 7 (2016). No. 1, Art. \#4, pp. 32-43.

doi: 10.14746/eip.2016.1.3 